\title{
Going Beyond Current Income
}

\author{
F. THOMAS JUSTER \\ GREG DUNCAN \\ University of Michigan
}

Current income may be an inadequate measure of employment quality because of variations in both wage and nonwage payments. Given a wage rate and complete homogeneity among workers with respect to hours worked and marketable skills, there are significant differences in nonwage benefits among jobs at a single point in time, such as the following: some jobs have more fringe benefits than others, some are more pleasant than others, some provide more autonomy than others, some require the worker to provide more input than others, and so on. In general terms, these differences can be categorized into variations in: (a) fringe benefits like health and medical care, pension rights, paid vacations, sick leave policy, disability insurance coverage, and the like; (b) general working conditions such as health and safety characteristics of the employment situation, the rigidity of the work schedule, and so on; and (c) what might broadly be characterized as the consumption benefits enjoyed by the workers-the leisure component of work time, the social relationships involved in a work situation, and so forth. 
A second, and perhaps more important, dimension of variation in work reward arises because of differences in earnings and nonwage benefits over time, as opposed to differences among homogeneous jobs at a single point in time: some jobs have a significant training component which is embodied in the wage rate, and thus confer higher future earnings, while others have little or no training and thus confer relatively constant future earnings; some jobs pay substantial retirement benefits with perfect certainty; some jobs provide opportunity for occupational advancement and income increases because they are (at least potentially) part of a promotional ladder, while others do not; some provide training which is widely transferable to other employment situations, while others do not; some jobs promise complete security in the form of tenure or the equivalent while others yield highly uncertain employment for some or all of the work force; and so on. These differences in expected lifetime earnings profiles are likely to be quantitatively more important than differences among homogeneous jobs in associated fringe benefits, working conditions, and consumption benefits. And the most important aspect of these lifetime profile differences are apt to be associated with differences in money income rather than in the nonmoney equivalents.

\section{THE MEASUREMENT OF INCOME FROM WORK}

Although this paper is concerned more with the nonmoney equivalents of job perquisites, it is impossible to discuss that subject adequately without paying a good bit of attention to what is meant by money income. The narrowest, and possibly the most appropriate, money income concept is the hourly wage rate. Income is then the product of wage rate and hours per time period. But variations in the amount and stability of hours, as well as in the hourly wage rate over the lifetime of an individual worker, are the two most important single dimensions of labor market income and neither is adequately captured by the standard measures of labor income. Typically, we talk 
about income as if it meant annual earnings, but we clearly need to think of income as having an extended time dimension into the future. Compared to wage rates, annual earnings pick up some of the time dimensions of income since they reflect variations in hours worked over the year. But variations in employment stability from year to year are by no means a negligible part of total variations in lifetime earnings.

In general, one can make a persuasive case that the most important dimension of money income in an employment situation is the expected earnings over the worker's lifetime, giving due regard to variations in the lifetime pattern of earnings attributable to factors like formal schooling, learning and training component on the job, retirement income provisions, income stability, income opportunities, and so forth. To settle for less than that in an income measure for employment is to place a thirty-year-old truck driver on a higher income plane than a thirty-year-old medical intern or legal apprentice or brand new Ph.D. college professor, none of which makes much sense when measured purely in money income terms without regard to the lifetime earnings streams associated with these different occupations. Furthermore, a straight annual income comparison gives no weight to the difference between a teenager and a middle-aged worker in identical "dead-end" employment situations with identical wage rates; the latter has settled into a dead-end niche from which there is no escape, while the former has not (yet) been consigned to the same niche.

In sum, if we think of "going beyond income" as going beyond conventional measurements of annual or weekly earnings, then the most important single dimension to measure in a social indicators context is money income measurements taken beyond the narrow confines of a week or a year and extended to the concept of an expected income over the lifetime.

The best one can probably do operationally in terms of implementing the lifetime income measurement is to estimate prospective earnings from cross-sectional data on earnings by years in the labor force, occupation, race, sex, and educational 
attainment. The resulting estimates would not, of course, be a valid measure of prospective earnings in current dollars, since the cross-section data would take no account of prospective inflation in wage rates generally. Instead they would be a reasonable representation of constant dollar prospective earnings for people in given employment situations.

\section{NONMONEY INCOME}

\section{FRINGE BENEFITS}

An important and generally quantifiable dimension of nonmoney income from employment consists of the collection of fringe benefits that can be characterized as equally costly to the employer as the provision of income in the form of direct wage payments. Fringe benefits are defined as goods, services, or deferred money income received by the employee but paid for (at least in the first instance) by the employer. ${ }^{1}$ The list of such items includes medical insurance, pension plans, paid vacation and sick leave, disability insurance, free or subsidized meals, vehicle parking, profit sharing, stock options, and so on. The distinguishing feature of this category of nonmoney income is that employers pay all or part of the cost of services that would otherwise have to be paid for by the employee, and the employee's effective money income is increased by the amount of the employer contribution or subsidy. Actually, employee income is increased even more since these services are not taxable when they are received, and are only taxable to the extent that direct financial benefits (from pensions, say) are actually received by the employee. Thus the money income equivalent of these kinds of services is actually more than the employer's contribution by the amount of tax savings to workers. On the other side, these and similar benefits are available generally without any choice on the part of employees. It is bound to be the case that some employees would not opt to acquire the equivalent services if they had to pay for them themselves and if they did not come as part of a package of benefits related to a particular work situation. If it is 
assumed, as seems generally reasonable, that employees are free to select jobs with various combinations of money and nonmoney income, an employee will tend to choose a job with the kind of fringe benefits package that suits his preferences. Thus complete fungibility of money and fringe benefit income is a reasonable assumption, and fringes are thus worth more than their cost by the amount of tax saving.

For the most part, the available data on fringe benefits are obtained from industry sources; they simply indicate the costs absorbed by firms in providing these kinds of employee benefits. That approach is probably correct in principle for obtaining good estimates of aggregate fringe benefits, but creates serious difficulties in attempting to associate fringe benefits with particular workers or with particular wage rates. The alternative-collection of data from workers in a household survey or perhaps a survey of firms matched with a survey of households-provides a better opportunity to combine money income and fringe benefit data, but almost certainly would result in worse estimates of the value of fringe benefits. This would be particularly true in areas like pension coverage, where the evidence suggests that many workers have little idea of the amount or kind of pension coverage being provided for them under employer plans.

Perhaps the principal valuation problem in these "standard" types of fringe benefits is how to handle pension contributions by employers. In the absence of fraud or deliberate mismanagement, it can be assumed that some group of employees will get the benefits paid in to the pension fund by the employer. But in the absence of complete vesting, the individual employee does not own his own pension rights and is able to obtain them only by meeting whatever requirements are laid down by the company plan. Thus, employees who are not under a fully vested pension plan have no assurance that they will receive any benefits at all. There are enough cases of deliberate company policy to create conditions where workers become ineligible, or to impose conditions that are in other respects highly undesirable as a precondition for continued eligibility, that pension 
plans not fully vested should clearly be assigned only a fraction of the value of fully vested pension plans. It is not obvious how the problem should be handled, but it does seem clear that nonvested plans are worth only a fraction of vested plans that involve the same cost to the employer.

\section{WORKING CONDITIONS}

Another collection of monetary equivalents, somewhat more difficult to value than fringe benefits, goes under the heading of general working conditions. Some working conditions such as health and safety of the work place, ventilation, lighting, restroom facilities, and lunchroom facilities, can be physically identified and impose clear-cut costs on the employer. Other job related characteristics are difficult to measure, difficult to evaluate, and may or may not impose employer costs. In this latter category are things like degree of work autonomy (ability to control hours, ability to function independently, flexibility of work schedule and work pace), the characteristics of grievance procedures, the nature of supervision, and the extent to which adequate resources are provided the employee who does his job well.

Of these working conditions variables, only those in the first category have any real prospect of being put into terms of monetary equivalents, and then only because they impose clear-cut and measurable costs on the employer. Assuming that the labor market functions competitively and efficiently, employees will again be able to opt for the combination of working conditions, fringe benefits, and salary which meets their own preferences about the relative importance of each. The working conditions variables in the second category are probably not quantifiable in dollar terms except as part of a residual explanation of wage differences that could otherwise not be explained. Moreover, there is some reason to believe that at least some of them do not have natural scales that are independent of employee characteristics. "Autonomy" is not a plus for all workers, nor is flexibility of scheduling and pace of work. 


\section{CONSUMPTION BENEFITS}

Probably the most difficult of the nonmonetary benefits to measure are those that can be put under the general heading of consumption benefits. In the most general sense, consumption benefits comprise the positive flow of satisfaction yielded by a work situation. They can include direct leisure where the job situation permits it, or such hard-to-quantify dimensions of job satisfaction as interest, challenge, social relationships, and enjoyment. With the exception of the leisure component of work, all the others represent subjective reactions on the part of individuals to a particular work situation, and it would be expected that a given job situation would elicit markedly different reactions from different individuals. ${ }^{2}$ Academicians frequently tend to regard the kind of work they do as interesting, fascinating, and challenging. They cannot imagine that others would evaluate it differently, or that people who work on assembly lines would find their job situation providing as many consumption benefits as academicians enjoy at their work.

But we may tend to delude ourselves with regard to the distribution of consumption benefits from work. While there is a positive correlation between working conditions and job satisfaction, there is less of an association between job content and job satisfaction. Personal evidence on that point concerns an operator of an automatic elevator (who was still holding a job from the days of manual elevators). As we rode from the first to the tenth floor, she asked a group of us economists what we did. "That sounds pretty dull to me," she remarked. Riding up and down on an elevator all day was a good deal more fun to this woman than running regressions or writing papers, and one suspects that that is not an uncommon view among many people.

There may be considerable pay off to analysis of consumption benefits defined as the leisure component of work. A notion that has a good deal of appeal to economists is that part of the observed wage rate differential across occupations with approximately the same skill requirements can be found in the degree 
to which work is really partly leisure. The argument does not apply only to aspects of the work situation which are contractual and precisely measurable, such as the provision of rest periods during the day as a matter of contract. A great many jobs differ markedly in the degree to which people are actually required to do something besides maintain a physical presence. Contrast the work situation faced by a night watchman in a factory or office building with that faced by a worker on an auto assembly line. Although the former has some responsibilities and must be there all the time, he or she also has ample opportunity to do a number of other things that are not dissimilar from what other people do when they are not working and not getting paid. One can read, daydream, play cards, listen to the radio, or perhaps watch television; while if one is on the auto assembly line, physical demands are probably continuous and substantial and leisure is obtained only during contract rest periods or relief time.

But that is just the tip of the iceberg. There are also a great many jobs in which people conventionally do not work very hard-they may have long and frequent coffee breaks, long periods when there is nothing required to do except wait for work to appear, and so forth. If jobs characterized by differences in the work-leisure ratio are identifiable in advance or by reputation, one would expect the wage rate to reflect that difference.

The chief distinction between the pure leisure component of work and consumption benefits broadly defined is largely one of measurability. In principle, one could obtain good measurements of time spent at work actually working and doing something else simply by obtaining time-budget estimates for work activities. Time and motion studies have a long and partly unsavory history among social scientists, but a time-budget study of work activity is not quite the same thing. A time-and-motion study asks how long it takes to perform a well-defined task, and then uses that estimate to calibrate the normal work load or work pace. A time-budget study of work activity simply asks what people do during each minute of the 
of ficial workday, and then categorizes activities into various functional dimensions of work and leisure.

The importance of differences among jobs and workers in the leisure proportion of working time may provide useful insights into issues like income equality. If an individual spends half of a nominal eight-hour day in activities that are better described as leisure than work, the effective hourly wage is twice the nominal one. Weekly or annual income is unaffected, but differences in wage rates, assuming flexibility in adjusting hours to preferred hours, are a better measure of income inequality than differences in total earnings over a week, a month, or a year. And it is a plausible speculation that a great many low-paying jobs are precisely ones where the leisure component is relatively larger than in jobs on average, while at least some high-paying jobs have exactly the opposite characteristic-a minimal leisure component and an intensive work component. In any event, this seems a significant dimension of nonmoney income, and one that lends itself toward quantification.

\section{ANALYTIC RELATIONSHIPS ${ }^{3}$}

The payoffs to measuring the nonwage dimensions of employment depend partly on the extent to which they vary independently of wage measures. If, for example, the historical trends in nonwage income closely parallel those of more easily measured earnings, there is little to be gained from the additional measurement. Similarly, the cross-sectional distribution of nonwage quality of employment indicators by race, sex, education level, and so on may have little to add to one's understanding of discrimination and human resource "investments" than if more accessible earnings measures are used.

We will discuss evidence, however, which suggests that there probably are payoffs to the measurement of nonwage aspects of jobs and that interpretations of various labor market phenomena change somewhat when nonwage factors are taken into 
account. Specifically, we will look at the extent to which certain fringe benefits and working conditions relate to labor income inequality, earnings differences between the sexes, and estimates of the "payoff" to education.

The data we use come from the 1972-1973 Quality of Employment Survey, which gathered information from a national sample of workers. ${ }^{4}$ Our analysis is restricted to those working at least 35 hours per week, thus excluding many who are only marginally attached to the labor force and for whom working conditions may be less important.

The Quality of Employment study contains dichotomous data on respondent perceptions of whether or not their job provides any of the following fringe benefits: vacation days with full pay, full-pay sick days, medical insurance for off-the-job illness or injury, life insurance for off-the-job death, retirement program, training programs to improve skills, profit sharing, free or discounted meals, and free or discounted merchandise.

Three working conditions can also be constructed from the data: dichotomous measures on the health and safety of working conditions and the extent to which the job provides stable employment throughout the year, and a trichotomous measure of the reported control of overtime hours and whether the respondent could refuse overtime work without penalty. ${ }^{5}$

\section{I.ABOR INCOME INEQUALITY}

A common way of investigating inequality in the distribution of labor income is to rank individuals by size of labor income, choose the top $10 \%$, and then compare their share of the total income with the share of the bottom $10 \%$. For workers from the Quality of Employment survey, the top $10 \%$ receive about $25 \%$ of total labor income, while the bottom $10 \%$ account for only about $3 \%$ of the total.

This inequality in labor income may either over- or understate inequality in a composite earnings measure that combines wage and nonwage components. The first step in such a comparison is to look at individuals at the extremes of the labor 
income distribution and calculate the "shares" of total fringe benefits and beneficial working conditions that they receive.

The data are summarized in Table 1, which has the shares of income, fringe benefits, and each of the three working conditions measures received by those at the top and bottom ends of the income distribution. One striking result, due in part to the low variability in the nonwage variables, is that all nonwage measures are more equally distributed than labor income itself.

Interestingly enough, workers in both the top and bottom ends of the labor income distribution receive less than the average number of fringe benefits. Those in the top $10 \%$ of income receive about $8 \%$ of the total number of fringe benefits available and those in the bottom decile have $6 \%$ of the total. These numbers, however, understate inequality in the value of fringe benefits, since many fringe benefits are proportional to, or at least vary with, the wage rate.

The shares of the three working conditions measures received by those at the top end of the income distribution exceed $10 \%$, but not by much, while workers at the bottom receive a slightly larger than average share of healthy and safe working conditions and overtime hours control, a slightly smaller than average share of employment stability. In contrast to fringe benefits, the share of beneficial working conditions received by those at the top and bottom ends of the labor income distribution is quite close to average.

\section{MALE-FEMALE EARNINGS DIFFERENTIALS}

Many empirical studies have shown marked earnings differences between men and women even after accounting for differences in characteristics that might affect productivity (e.g., education, experience). Those studies, however, have analyzed a pecuniary work payment measure such as annual income or hourly wage. Looking at the extent to which females differ from males in the receipt of fringe benefits and beneficial 


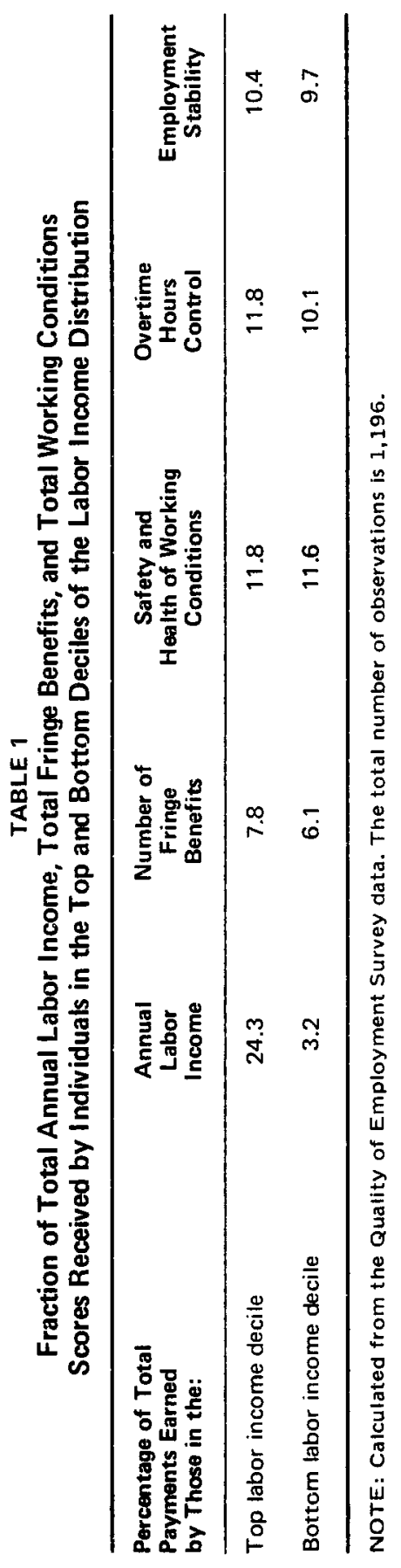


working conditions provides a more complete picture of earnings differentials.

Expanding the earnings concept to include the nonwage measures may either increase or decrease estimated differences. To the extent that the nonwage measures compensate for income differentials, total earnings differences are overstated by a simple income measure. If nonwage measures reinforce differences in income, then total earnings differences will be understated.

Multiple regression is used to investigate the wage and nonwage differentials with each of the payment variables regressed on a common set of explanatory variables. To control for training differences, the regressions include years of education and labor market experience. ${ }^{6}$ The expected nonlinear earnings-experience profile (Mincer, 1974) is taken into account by including the square of years of experience as an additional predictor. A measure of current job tenure is included to control for additional productivity differences which may arise from different amounts of training specific to the firm, and respondent reports of a physical condition that limits the amount of work which can be done is included to control for differences in individual physical and mental health. The net payment differential between men and women is reflected by a dummy variable "whether female." The coefficient on this variable will show the extent to which women differ from men in the receipt of income, fringe benefits, or beneficial working conditions. Since the various dependent variables are scaled in different ways, each is standardized so that coefficients on the "whether female" variables refer to the fraction of a standard deviation of the payment variable that white women differ from white men. ${ }^{7}$

The regression results are presented in Table 2. As expected, white women earn substantially less income than similarly qualified white men. The --.66 coefficient for white females in the Annual Income column shows that, when the effects of education and experience are taken into account, white females earn about two-thirds of a standard deviation less income than 


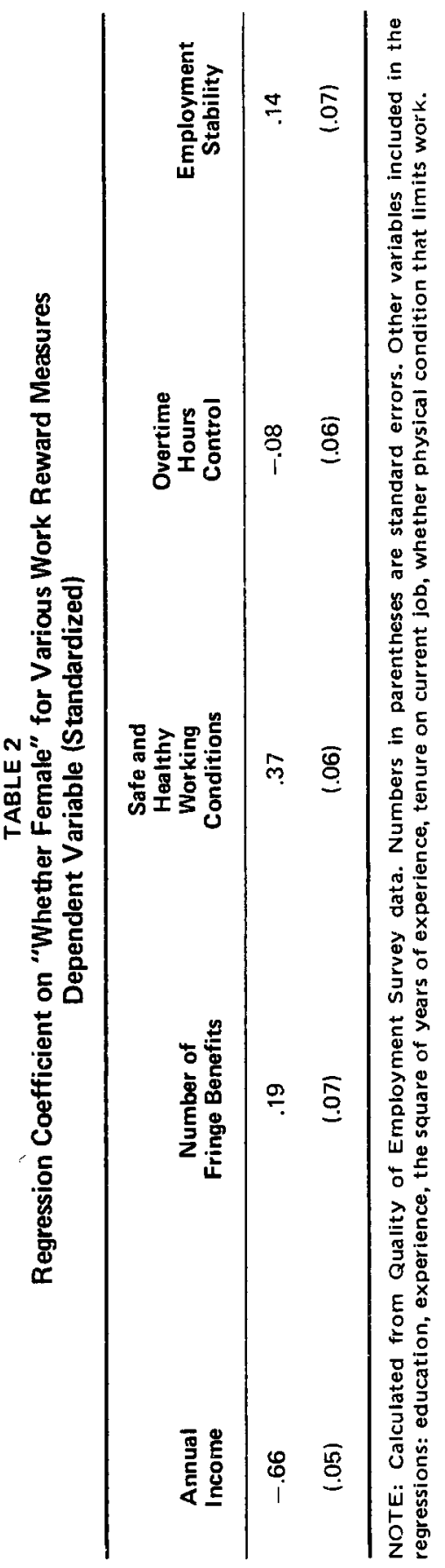


white males. Since the income of respondents had a standard deviation of $\$ 6,564$, this income deficit amounts to about $\$ 4,400$.

The other columns of Table 2, however, show that white women are partially compensated for this difference by receiving a significantly higher number of fringe benefits, healthier and safer working conditions, and more stable employment. Women have an insignificantly smaller amount of overtime hours control than white men.

The net result of nonwage dimensions of work reward on the estimated total earnings differences between white men and women will depend upon the way in which the various rewards are combined into a measure of total earnings. If fringe benefits, the health and safety of work, and employment stability are sufficiently important components of total earnings, the simple income differences could even be reversed. On the other hand, working conditions variables could doubtless be found for which women score lower than men, and if these are given sufficient weight in a total earnings measure, income differences may actually understate total earnings differentials. However, these fringe benefit and working conditions measures are fairly comprehensive. The notion that women tend to work in occupations that are safer than average and provide more stable employment throughout the year is certainly not unreasonable. On the whole, the overall earnings differentials by sex are less than observed pecuniary differentials, although nonwage factors would need very heavy weights before they would offset earnings differences.

\section{THE PAYOFF TO EDUCATION}

Studies which estimate the labor market "payoff" to formal education invariably use a pecuniary payoff measure. Such a measure will provide an accurate estimate of the total payoff only if fringe benefits and other important nonwage variables are independent of education. To check for this independence, we have estimated regressions of each of the nonwage variables on the predictors of a simple earnings function as follows: years 


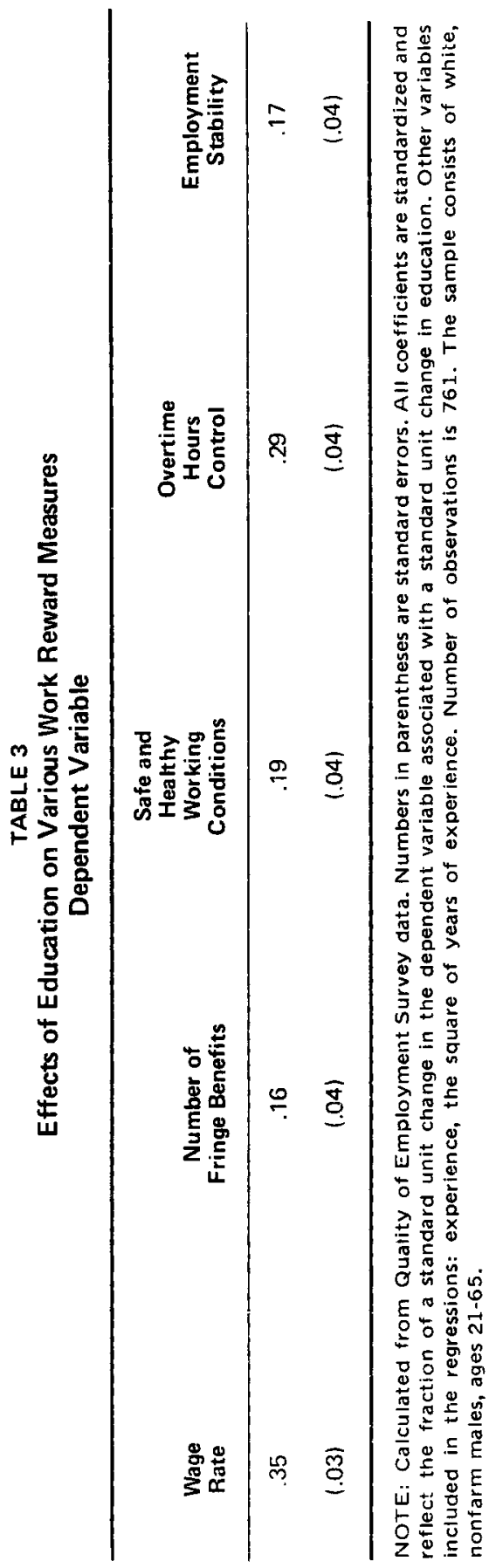


of education, experience, and the square of years of experience. The estimated coefficients of education are shown in Table 3. Results on the importance of education for these fringe and working condition benefits are dramatic and unambiguous; education is a significant determinant of all four variables. The coefficients on education are at least four times their standard errors in every case. This suggests that pecuniary earnings understate the importance of education on a more complete earnings measure. Experimentation with plausible utility functions which combine the wage and nonwage variables indicates that the importance of education may be understated by as much as $35 \%$. Thus, wage differentials unambiguously understate the returns to formal schooling as compared to total wage and nonwage earnings, a result consistent with other studies of the importance of nonwage returns in estimating the total return to schooling (Juster, forthcoming).

\section{SUMMARY}

Since quantification of employment dimensions other than current income is not costless, it is important to consider the benefits of further measurement.

The most straightforward and immediate extension is to measure expected labor income over a lifetime rather than simply annual income. This is not difficult to do and would give a better picture of the remuneration associated with various work situations.

A second set of work rewards are the fringe benefits. Most fringe benefits can be quantified into dollar terms (although perhaps not by the employees themselves). Our evidence suggests that even rough measurement of these fringe benefits affects the estimated inequality in the distribution of earnings.

Working conditions constitute a third dimension of work reward. Many of them pose formidable measurement problems, although we have shown that some that have been measured can affect the way in which certain labor market phenomena are viewed. 
Consumption benefits constitute a final category of nonwage job payments. We have no empirical findings, although we suspect that the leisure component of work is the consumption benefit most susceptible to measurement and perhaps would have a high payoff for understanding and monitoring the labor market.

\section{NOTES}

1. Logically, and probably empirically as well, fringe benefits are paid for by employees in the form of lower money wages.

2. A cogent discussion of the personal and environmental antecedents of job satisfaction is presented in the Seashore and Taber article in this volume.

3. Many of the results in this section are taken from Duncan (1974).

4. The survey is documented in Quinn and Shepard (1974).

5. Additional data on job autonomy, resource adequacy, job satisfaction, and a host of other measures were also gathered in the survey. This initial analysis is restricted to measures that are most likely to impose measurable costs on employers and those which a vast majority of workers would consider unambiguous benefits.

6. The experience variable is measured from responses to the question "About how many years in total have you worked for pay since you were 16 years old?"

7. Since the number of blacks in the Quality of Employment Survey is small, we restrict our attention to white men and women.

\section{REFERENCES}

DUNCAN, G. J. (1974) "Nonpecuniary work rewards: implications for studies of earnings functions, discrimination and labor union effects." Ph.D. dissertation. University of Michigan.

JUSTER, F. T. (forthcoming) Income, Education and Human Behavior. Carnegie Commission on Higher Education.

MINCER, J. (1974) Schooling, Experience, and Earnings. New York: National Bureau of Economic Research.

QUINN, R. P. and L. J. SHEPARD (1974) The 1972-73 Quality of Employment Survey: Descriptive Statistics, with Comparison Data from the 1969-70 Survey of Working Conditions. Ann Arbor: University of Michigan Survey Research Center, Institute for Social Research. 